\title{
How Persistent Is the Occupation-Education Mismatch in Canada?
}

\author{
Xuyang Chen and Maxime Fougère \\ Employment and Social Development Canada, 140 Promenade du Portage, Phase 4, Gatineau, QC, Canada K1A 0J9 \\ Correspondence should be addressed to Maxime Fougère; maxime.fougere@hrsdc-rhdcc.gc.ca
}

Received 30 October 2013; Accepted 24 November 2013; Published 23 January 2014

Academic Editors: J. Le Gallo and R. Wright

Copyright (C 2014 X. Chen and M. Fougère. This is an open access article distributed under the Creative Commons Attribution License, which permits unrestricted use, distribution, and reproduction in any medium, provided the original work is properly cited.

This paper investigates the duration of overqualification in Canada, the time-varying probability of leaving overqualification, and the wage consequences associated with the transition. The paper also applies a survival analysis approach to examine the impact of key driving factors on the probability of transitioning from overqualification to a job match using a proportional hazard (Cox) model. The analysis shows that within a 5-year period, an overqualified worker has a 22 percent probability of transitioning to an occupation that matches the education level. The probability of transition also decreases quickly over time, thus lowering the chances of finding a job match after 12 months. Regression analyses also provide evidence that overqualified workers with short tenure are more likely to transition than workers with medium to long tenure. Finally, job-related training nearly doubles the chance of transitioning out of overqualification.

\section{Introduction}

It is well known that the level of education has significantly risen in Canada during the past few decades. Over the same period, we also observe a trend increase in the incidence of overqualified workers. Human capital investment is a key determinant of economic growth. However, not only do we need to invest in the supply of skills to help support growth, we also need to ensure that the skills of Canadian workers are used efficiently. Carr and Chen [1] found that about one in three Canadian workers were overqualified for their jobs in 2008. Also, according to the OECD [2], overqualified workers earn about 20 percent less on average than their matched counterparts in Canada.

For an individual in a skills mismatch situation, overqualification may either be transitory, persistent, or permanent. In the case of a persistent or permanent mismatch situation, the cumulative loss in wages and productivity could become large and costly over time. Persistent overqualification also leads to skill obsolescence. While matched workers accumulate more human capital through experience, overeducated workers do not have the chance to use their skills and lose valuable work experience. This eventually leads to a depreciation of their human capital. Moreover, the persistence of overqualification inevitably reduces further the probability of finding an appropriate job that matches their skills set as firms use information on previous employment history in their hiring decisions.

Although there is a wide literature on the incidence of skills mismatch, the issue of persistence has not been studied much. Among the few studies, Green et al. [3], Johnson [4], and Jovanovic [5] argue that job mismatch would occur predominantly at the early stage of an individual's career and eventually disappear without the need for specific action or policy. In contrast, Spence [6] suggests that overqualification is a long-term situation and that individuals systematically acquire more skills than the jobs usually require. However, these arguments are mainly theoretical and to our knowledge not much empirical evidence has been provided on the degree of persistence of skills mismatch.

Overall, the extent to which the state of mismatch is transitory or permanent and how the transition probability evolves over time is unknown. This issue, however, is very important to help identify policy levers. If most mismatch situations are transitory and relatively short-lived, the need to develop policy instrument becomes questionable. On the other hand, if a significant proportion of skill mismatch 
remains persistent and eventually becomes permanent, the need for appropriate policy intervention should be more seriously considered.

This paper's key objectives are twofold. First, using the Survey of Labour and Income Dynamics (Panel 5, SLID 2002 to 2007), this paper seeks to investigate the duration of overqualification in Canada, the time-varying probability of leaving overqualification, and the wage consequences associated with the transition. Second, by specifying a survival model, the paper explores the impacts of key driving factors on the probability of transitioning from overqualification to a job match.

The remainder of this paper is divided as follows. Section 2 discusses the theoretical framework. Section 3 reviews some recent relevant literature. Section 4 discusses the data and methods used for the analysis. Section 5 presents the estimation results and marginal effects. Finally, Section 6 concludes.

\section{Theoretical Background}

Applying a simple form of matching function [7], the probability for an unemployed worker to find a job during a unit of time can be expressed as follows:

$$
P=\frac{m(U, V)}{U},
$$

where $U$ is the number of unemployed workers, $V$ is the number of vacancies, and $m(U, V)$ is the number of jobs formed during a given time period. A job match can either be a transition from unemployment or from a job mismatch. If we assume that employed job seekers have the same search behaviour and reservation wage as unemployed job seekers, the same matching function can be applied to employed job seekers (see Petrongolo and Pissarides [8] for more details).

Muysken and Weel [9] have extended the theoretical framework developed by Pissarides [7] by introducing a matching process focusing on the transitions from underemployment (skilled workers working in unskilled jobs) to skilled jobs. This approach is mainly driven by labour demand: firms in skilled sectors create skilled jobs and seek workers having at least the level of skills (or human capital) $\widehat{h}$ to fill the vacancies, while overqualified workers prefer to work in a skilled job that better matches their education for a higher wage. In this setting, $U$ represents the number of underemployed workers (or overqualified workers) and $V$ represents the number of vacancies of skilled jobs. Assuming that the probability of finding a job match remains constant over time and follows a stationary process, the mean duration of underemployment or search duration can be expressed as

$$
D=\frac{1}{m(U, V, h / \widehat{h}) / U}, \quad h \geq \widehat{h} .
$$

However, Pissarides [10], Devine and Kiefer [11], and Heckman and Borjas [12] reject the assumption that the probability of finding a job follows a stationary process. Instead, they argue that the skill of an unemployed or underemployed worker will tend to depreciate over time and accordingly, the probability of finding a job match will decrease with the duration of underemployment.

In this paper, we assume that the skill of an overqualified worker depreciates over time and express human capital endowment during the period of underemployment as

$$
h_{t}=h e^{-r t}
$$

where $h$ is the original human capital at the beginning, $h_{t}$ is the remaining human capital of an overqualified worker at time $t$, and $r$ is the discount rate.

Over time, workers who remain overqualified become less attractive to employers due to human capital depreciation. Accordingly, the supply of skilled job offers will be reduced in the next period and the probability of transitioning from overqualification to match will decrease (Pissarides $[7,10]$ give a detailed description of the equation). Therefore, in period $t$, the matching probability between a skilled job and an overqualified worker will depend on the duration of overqualification, which we approximate by job tenure.

We assume that at the beginning of the overqualification period, workers' human capital endowment $h$ matches the requirement for the skilled occupations $\widehat{h}$. After a period $\tau$, the level of human capital depreciates to $h_{\tau}$ which is lower than $\hat{h}$. In other words, after period $\tau$, the overqualified workers who did not find a match are no longer attractive to employers from the skilled sector. This may be further examined in the empirical model by adding a time dependent variable $I_{t}(T>\tau)$ to measure the time point after which the remaining human capital of an overqualified worker falls below the requirement for a skilled job $\left(I_{t}\left(h_{t}>\widehat{h}\right)\right)$.

On the other hand, taking job-related training or education may help restock an individual's human capital. Under this hypothesis, we assume that overqualified workers who take job-related training will increase their probability of transitioning to a skilled job match. Finally, a matching probability between an overqualified worker and a skilled job can be expressed as

$$
p_{i, t}=f\left(T_{i, t}, \operatorname{Tr}_{i, t}, I_{i, t}, X_{i}\right),
$$

where $T_{i, t}$ refers to the duration of overqualification at time $t, \operatorname{Tr}_{i, t}$ refers to the job-related training or education, $I_{i, t}$ refers to the indicator for the cut-off time of losing enough skill, and $X_{i}$ refers to individual characteristics and behaviors.

\section{Overview of the Skills Mismatches Literature}

There is a growing body of literature on skill mismatch. In Canada, most studies so far have focused on the incidence of overqualification and its effect on earnings. For example, using the National Graduates Survey (NGS), Frenette [13, 14] and Finnie [15] find that roughly between $30 \%$ and $40 \%$ of recent graduates experience a skill mismatch. Using the Survey of Labour and Income Dynamics (SLID), Carr and Chen [1] find similar results among prime-aged workers. 
These studies also find that the wage penalty associated with overqualification is substantial, compared with workers who have the right occupation-education match. In general, these results are in line with findings using American or other OECD country data [2].

Although there is a substantial literature on the incidence of overqualification, the issue of persistence has received little attention in Canada. One notable exception is Frenette [14] who briefly discusses the issue of persistence in overqualification among recent graduates. Based on an interview result from the NGS, he finds evidence that a significant proportion of workers remain overeducated between two and five years after graduation.

A few recent studies have examined the issue of persistence in overqualification for the US, Sweden, Australia, and Belgium. Overall, these studies present useful stylised facts on the duration of overqualification, but they do not provide empirical evidence on the determinants of the duration of overqualification and do not examine the probability of leaving overqualification. Among these, Dolton and Vignoles [16] find that a majority of workers in the US who are overeducated in a given year are still overeducated six years later. For the US, Rubb [17] finds that the majority of individuals who are overqualified for their jobs in a given year remain overqualified the following year. For Sweden, Böhlmark [18] finds that $61 \%$ of younger graduates who were overqualified in 1981 remain overqualified in the following years. For Australia, McGuinness and Wooden [19] examine overskilling duration and conclude that only 25 percent of overskilled workers transition to a matched job within a period of three years. In Belgium, Schatteman and Verhaest [20] examine overeducated workers and find that a large proportion of graduates remain overeducated for more than seven years. Finally, de Grip and van Loo [21] look at the relationship between overeducation, skill obsolescence, and training. They suggest that the insufficient practice of skills during the overeducation may lead to atrophy of skills and that job-related training may contribute to the reduction in skills mismatch.

\section{Data and Method}

4.1. Data Source. In the literature on skills mismatch, skill requirement has been measured in three different ways: from job analysis, worker self-assessment, or realised matches. According to Hartog [22], the job analysis method is the most attractive one because of its objectivity, clear definitions, and detailed measurement instructions. Compared to the job analysis method, the worker self-assessment (WA) method has the advantage of drawing on all local, up-to-date information but lacks rigorous instructions. Consequently, WA measurement can easily be biased for individuals who cannot accurately describe the requirements for their job. Finally, realized matches (RM) use the mean (or mode of distribution) of required education derived from respondents' job or occupation as a measure of the demand. This measure is not precise enough to uncover the technological requirements of a job. In this paper, the approach we use to define overqualification is based on the job analysis method. Using the National Occupational Classification (NOC) matrix, we define a worker as over-qualified if the individual's level of education exceeds the education level required by the occupation at the end of 2002.

The data used in the analysis are drawn from the Survey of Labour and Income Dynamics (SLID panel 5, from 2002 to 2007). The SLID is a household survey that provides longitudinal followup on Canadian families and individuals' demographic background, income, education level, labour market activities, and financial situation. The SLID also collects information on workers by occupation at the fourdigit level and with employer's industry code. This allows us to classify individuals by education and skill level and identify those who are overqualified and those who change jobs between occupations and industries over time. According to the NOC code obtained from each individual's current job, all workers in the sample are assigned a skill level in each given year. At the four-digit level, the 520 occupations can be reclassified within four skill levels (A, B, C, and D).

A: occupations usually requiring university education;

B: occupations usually requiring college education or apprenticeship training;

C: occupations requiring secondary school or occupation-specific training;

D: occupations requiring only on-the-job training.

Here, skill level is a job characteristic, while education is a characteristic of the individual. In our sample, 2882 primeaged workers who were overqualified for their occupation in 2002 are followed over a 6-year period.

4.2. Survival Model. We estimate a proportional hazard [23] model using monthly data to analyse transitions from overqualification to a job match. The hazard rate measures the probability that an individual will transition out of overqualification in a period $(t, t+\Delta t)$, given that this individual remains overqualified at time $t$. The Cox model captures the impacts of training, immigration status, and tenure on the probability of transition. According to Frank [24], job immobility may be a potential cause of overqualification. In this model, we also include an indicator to measure if changing employer or industry can improve the chance of moving out of overqualification. Finally, $\lambda(t \mid X)$ denotes the hazard function and $\lambda_{0}(t)$ denotes the baseline hazard function at time $t$. The model in terms of the hazard function at time $t$ is

$$
\begin{aligned}
& \lambda(t \mid X) \\
& =\lambda_{0}(t) \exp \left(\beta_{1} \text { Tenure }+\beta_{2}\right. \text { Training } \\
& +\beta_{2} \text { Tenure } * I(t>\tau)+\beta_{3} \operatorname{Imm} \\
& \left.+\beta_{4} \text { Age }+\beta_{5} \text { Gender }+\beta_{6} \mathrm{Ci}+\beta_{7} \mathrm{Edu}\right) \text {. }
\end{aligned}
$$


TABLE 1: Wage changes between 2002 and 2007.

\begin{tabular}{lcccc}
\hline & \multicolumn{2}{c}{ Remaining in overqualification } & \multicolumn{2}{c}{ Transition to a matched occupation } \\
& Mean & Median & Mean & Median \\
\hline Hourly wage, 2002 & $\$ 16.56$ & $\$ 15.00$ & $\$ 16.81$ & $\$ 15.00$ \\
Hourly wage, 2007 & $\$ 19.71$ & $\$ 17.68$ & $\$ 23.72$ & $41.1 \%$ \\
Wage increase, 2002-2007 & $19.0 \%$ & $17.9 \%$ & $40.8 \%$ \\
\hline
\end{tabular}

Source: authors' calculation from the SLID, panel 5, 2002-2007.

Explanatory variables are mentioned as follows.

(i) Tenure: the number of months of work in the current main job.

(ii) Training: 1 if individual takes job-related training or education, else 0 .

(iii) $I(t>\tau)$ : dummy variable for the specific time point.

(iv) Imm: set of dummy variables for the immigrant status: recent immigrant (less than 5 years), established immigrant (more than 5 years), and native born.

(v) Age: set of dummy variables for each age in the sample.

(vi) Gender: male $=1$, else 0 .

(vii) Educ $_{i}$ : set of dummy variables for education level: postsecondary or university.

(viii) Ci: 1 if individual changes job between industry, else 0 .

Under the assumption that the human capital of overqualified workers depreciates over time, the resulting probability of transitioning out of overqualification will decrease until time $\tau$, the point where the individual becomes no longer attractive to the employers from the skilled sector. We therefore expect that the negative impact of tenure on the hazard rate will depend on time and violate the proportional assumption of the Cox model. We also identify the approximate time point $\tau$ by comparing Nelson-Aalen cumulative hazard estimates among workers with different tenures and then combine tenure and a time depending indicator $I(t>\tau)$ in the modeling process to compensate for the changing impacts.

\section{Empirical Results}

We first present some descriptive statistics, including wage changes associated with transitions and the results of the Kaplan-Meier failure function. This is followed by a presentation of the estimation results of the Cox model.

5.1. Wage Changes Associated with Transitions. Table 1 compares wage changes between 2002 and 2007 for overqualified workers who transition to a matched occupation and those who remain overqualified. As can be seen, wage increases associated with transition are substantial. For workers who transitioned to a matched occupation, nominal hourly wage increased by about 41 percent, compared to 19 percent for the mean hourly wage (and 17 percent for the median wage) for workers who remained overqualified. This clearly demonstrates that the wage loss associated with being overqualified is quite significant.

5.2. Transition Rates by Group. Table 2 summarizes the results of the failure function by individual and worker's characteristics. The failure function is presented at five different points in time $(12,24,36,48$, and 60 months after the end of 2002). By gender, the probability for men of transitioning out of overqualification is about $8.5 \%$ within the first year, $13.5 \%$ after 24 months, $17.5 \%$ after 36 months, $20.5 \%$ after 48 months, and $22 \%$ after 60 months. The probability of transitioning to a matched occupation is about the same for overqualified women, reaching a little over $23 \%$ after 60 months.

This result clearly indicates that the probability of transition decreases quickly over time. It also suggests that the vast majority of overqualified workers remain in this situation throughout their career, which is in line with the assumption that overeducated individuals eventually become less attractive to employers.

Overqualified workers with post-secondary education and university degree also have a probability of transitioning out of overqualification that is similar at each point in time. However, when we look by age group and immigrant status, we find substantial variations in the probability of transitioning to a matched position. Workers aged $25-34$ have the highest probability of transitioning, reaching $28 \%$ after 60 months, compared with $22 \%$ and $18 \%$ for age groups $35-44$ and $45-54$, respectively. By immigrant status, nonimmigrants record the highest transition rates for the whole period, reaching a probability of $23.8 \%$ after 60 months, followed by recent immigrants $(18.6 \%)$ and established immigrants (13.4\%).

As expected, overqualified workers who take job-related training record much higher transition rates, nearly twice the probability achieved for workers who do not take job-related training. This suggests that work-related training helps to transition out of overqualification. The results also reveal that changing industry of work is associated with a much higher probability of transition during the whole period $(19.5 \%$ versus $5.6 \%$ after 12 months and $47.5 \%$ versus $19.5 \%$ after 60 months). In fact, nearly half of all transitions are associated with industry mobility.

5.3. Cut-Off Time Point $\tau$. The use of the Kaplan-Meier failure function can help illustrate the overall transition patterns 


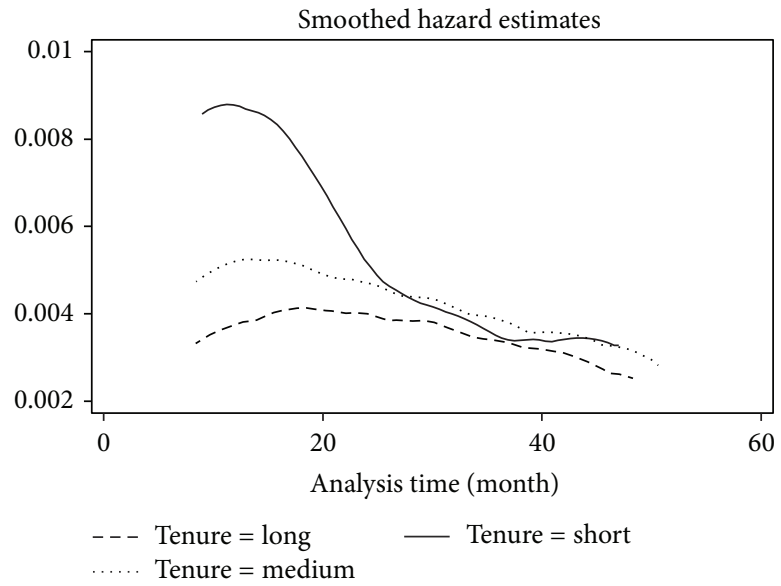

(a)

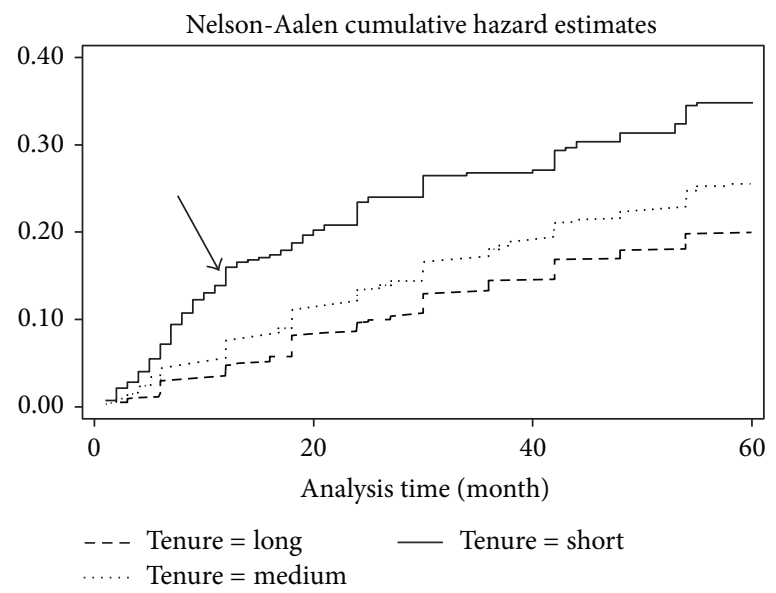

(b)

FIGURE 1: Estimated smoothed and cumulative hazard functions by tenure.

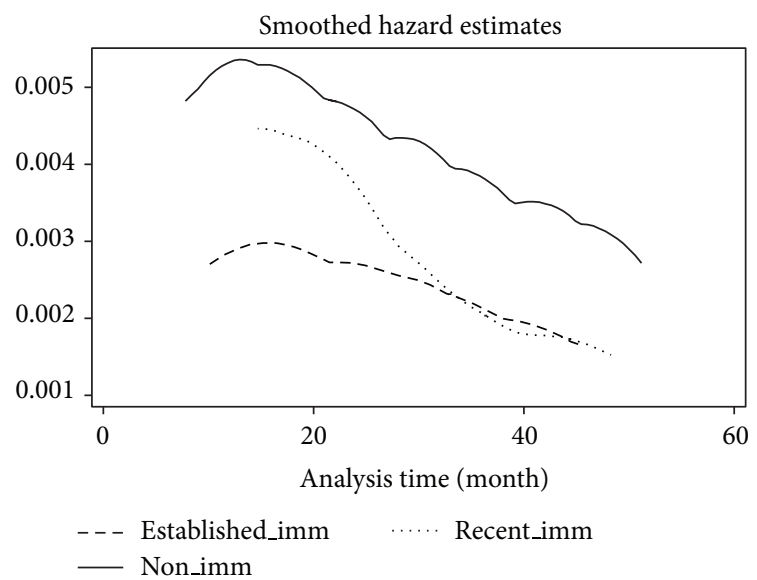

(a)

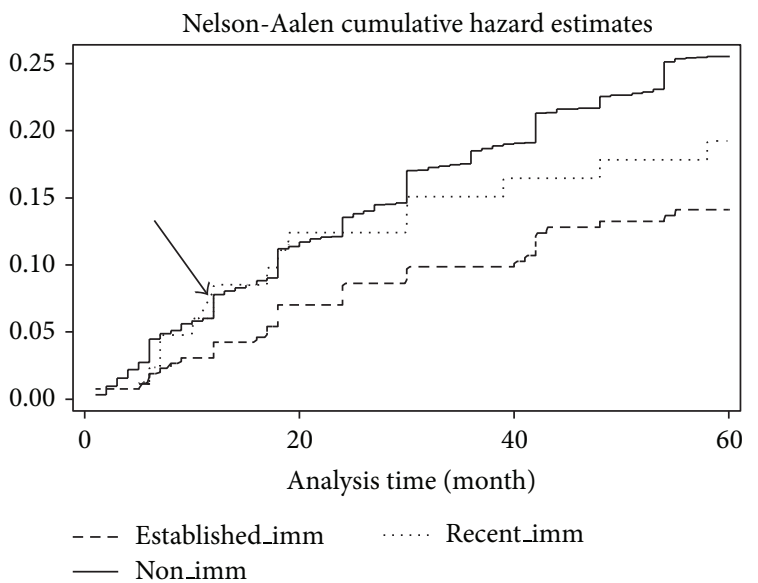

(b)

FIGURE 2: Estimated smoothed and cumulative hazard functions by immigrant status.

and variations by individual and job characteristics. However, these transition estimates are not precise enough to identify the time point $\tau$, the approximate time after which the remaining human capital of an overqualified worker has fallen below the level required for a skilled job. We expect the hazard function of workers with short and medium tenure to converge after $\tau$ months. Both smooth hazard and NelsonAalen estimates can provide subjective and useful graphical assessments. Therefore, we use these plots to display the marginal effect of this potentially time-varying covariate, and diagnose $\tau$.

Figure 1 presents the smooth hazard and Nelson-Aalen estimates stratified by tenure. The smoothed hazard function shows that compared to workers with medium (1 to 4 years) and long tenure (5 years or more), the hazard rate of overqualified workers with short tenure (less than 1 year) is much higher at the beginning and then drops quickly and converges with the other two groups after some time point $\tau$. However, the smoothed hazard function is only one type of "moving average" statistic. We further the Nelson-Aalen estimate, an empirical cumulative hazard of transitioning to a job match as a function of the length of the overqualification spell, to identify $\tau$ in a more precise way.

From Nelson-Aalen estimate, it can be seen that within 12 months, the cumulative hazard function for individuals with short tenure is markedly larger than for the other two groups. However, after approximately 12 months, workers with short and medium tenure have roughly the same slope, suggesting that the hazard functions of these two groups are about the same. We therefore define $\tau=12$ months after the end of 2002 in the sample (since the average job duration of the short tenure group is about 7 months, $\tau$ may be also considered as a 19-month period from the beginning of overqualification).

Among the variables, immigration status is also found to be a time-varying covariate. As shown in Figure 2, hazard rates of recent immigrants are much higher than for established immigrants at the beginning and then decrease quickly and converge with those of established immigrants 
TABLE 2: Probability of transitioning to an occupation that correctly matches an individual's education level (Kaplan-Meier estimator).

\begin{tabular}{|c|c|c|c|c|c|c|c|c|c|c|}
\hline & \multicolumn{5}{|c|}{ Transition to a matched occupation } & \multicolumn{5}{|c|}{ Remaining in overqualification } \\
\hline & 12 months & 24 months & 36 months & 48 months & 60 months & 12 months & 24 months & 36 months & 48 months & 60 months \\
\hline Male & $8.4 \%$ & $13.5 \%$ & $16.7 \%$ & $20.0 \%$ & $21.8 \%$ & $91.6 \%$ & $86.5 \%$ & $83.3 \%$ & $80.1 \%$ & $78.2 \%$ \\
\hline Female & $8.5 \%$ & $13.4 \%$ & $17.8 \%$ & $21.0 \%$ & $23.3 \%$ & $91.5 \%$ & $86.6 \%$ & $82.2 \%$ & $79.0 \%$ & $76.7 \%$ \\
\hline Age: $25-34$ & $11.1 \%$ & $18.1 \%$ & $21.9 \%$ & $26.0 \%$ & $28.4 \%$ & $88.9 \%$ & $81.9 \%$ & $78.1 \%$ & $74.0 \%$ & $71.6 \%$ \\
\hline Age: $35-44$ & $8.0 \%$ & $12.9 \%$ & $17.0 \%$ & $20.2 \%$ & $22.0 \%$ & $92.0 \%$ & $87.1 \%$ & $83.0 \%$ & $79.8 \%$ & $78.0 \%$ \\
\hline Age: $45-54$ & $6.7 \%$ & $9.9 \%$ & $13.4 \%$ & $15.9 \%$ & $18.1 \%$ & $93.3 \%$ & $90.2 \%$ & $86.6 \%$ & $84.1 \%$ & $81.9 \%$ \\
\hline Recent immigrants & $7.0 \%$ & $12.8 \%$ & $15.1 \%$ & $17.4 \%$ & $18.6 \%$ & $93.0 \%$ & $87.2 \%$ & $84.9 \%$ & $82.6 \%$ & $81.4 \%$ \\
\hline $\begin{array}{l}\text { Established } \\
\text { immigrants }\end{array}$ & $4.5 \%$ & $8.7 \%$ & $9.8 \%$ & $12.8 \%$ & $13.4 \%$ & $95.5 \%$ & $91.4 \%$ & $90.2 \%$ & $87.2 \%$ & $86.7 \%$ \\
\hline Nonimmigrants & $8.9 \%$ & $14.0 \%$ & $18.2 \%$ & $21.5 \%$ & $23.8 \%$ & $91.1 \%$ & $86.0 \%$ & $81.1 \%$ & $78.5 \%$ & $76.2 \%$ \\
\hline $\begin{array}{l}\text { Tenure: less than } 1 \\
\text { year }\end{array}$ & $14.9 \%$ & $21.0 \%$ & $23.7 \%$ & $27.1 \%$ & $29.6 \%$ & $85.1 \%$ & $79.0 \%$ & $76.3 \%$ & $72.9 \%$ & $70.4 \%$ \\
\hline Tenure: 1 to 4 years & $9.6 \%$ & $14.8 \%$ & $18.7 \%$ & $22.1 \%$ & $24.5 \%$ & $90.4 \%$ & $85.2 \%$ & $81.3 \%$ & $77.9 \%$ & $75.5 \%$ \\
\hline $\begin{array}{l}\text { Tenure: } 5 \text { or more } \\
\text { years }\end{array}$ & $5.6 \%$ & $10.0 \%$ & $14.2 \%$ & $17.2 \%$ & $19.0 \%$ & $94.5 \%$ & $90.0 \%$ & $85.8 \%$ & $82.8 \%$ & $81.0 \%$ \\
\hline $\begin{array}{l}\text { Job-related } \\
\text { training: yes }\end{array}$ & $10.3 \%$ & $16.7 \%$ & $22.0 \%$ & $26.9 \%$ & $29.3 \%$ & $89.7 \%$ & $83.3 \%$ & $78.0 \%$ & $73.1 \%$ & $70.7 \%$ \\
\hline $\begin{array}{l}\text { Job-related } \\
\text { training: no }\end{array}$ & $6.7 \%$ & $10.1 \%$ & $12.4 \%$ & $13.9 \%$ & $15.8 \%$ & $93.4 \%$ & $89.9 \%$ & $87.6 \%$ & $86.1 \%$ & $84.2 \%$ \\
\hline $\begin{array}{l}\text { Changing industry: } \\
\text { yes }\end{array}$ & $19.5 \%$ & $29.5 \%$ & $36.7 \%$ & $43.9 \%$ & $47.1 \%$ & $80.5 \%$ & $70.5 \%$ & $63.3 \%$ & $56.1 \%$ & $52.9 \%$ \\
\hline $\begin{array}{l}\text { Changing industry: } \\
\text { no }\end{array}$ & $5.6 \%$ & $9.4 \%$ & $13.4 \%$ & $16.7 \%$ & $19.5 \%$ & $94.4 \%$ & $90.6 \%$ & $86.6 \%$ & $83.3 \%$ & $80.5 \%$ \\
\hline $\begin{array}{l}\text { Education: } \\
\text { university }\end{array}$ & $8.5 \%$ & $12.9 \%$ & $16.5 \%$ & $18.9 \%$ & $21.1 \%$ & $91.5 \%$ & $87.1 \%$ & $83.6 \%$ & $81.2 \%$ & $78.9 \%$ \\
\hline $\begin{array}{l}\text { Education: } \\
\text { postsecondary }\end{array}$ & $8.5 \%$ & $13.7 \%$ & $17.6 \%$ & $21.1 \%$ & $23.2 \%$ & $91.5 \%$ & $86.3 \%$ & $82.4 \%$ & $78.9 \%$ & $76.8 \%$ \\
\hline
\end{tabular}

Source: authors' calculation from the SLID, panel 5, 2002-2007.

after some period. Nelson-Aalen estimates show that the length of this period is about 12 months again. However, since the average period that recent immigrants have arrived in Canada at the end of 2002 is about 30 months, recent immigrants may be considered to have the same hazard rate as established immigrants after having arrived in Canada for 42 months.

5.4. Results from the Cox Model. Table 3 summarizes the estimation results of the Cox model fitted to the data. Overall, the model results from the Cox model are broadly in line with the descriptive findings. In particular, the results support the assumption for the existence of a cutoff point $\tau$ after which the remaining overqualified workers are no longer attractive to employers from the skilled sector and nearly have a zero probability of transition to a job match. As shown in Table 3, both short tenure and the covariate short tenure $* I(t>$ 12 month) are statistically significant at a $99 \%$ degree of confidence. Furthermore, the positive regression coefficient of the covariate short tenure (2.58) is offset by the negative estimate of short tenure $* I(t>12$ month $)(-3.0)$. This suggests that compared with medium tenure, short tenure is associated with a higher hazard function for up to 12 months, after which there is no significant effect. We also find no evidence that medium and long tenure workers have a different transition probability.

As expected, job-related training positively influences the probability of transitioning out of overqualification and its impact is statistically significant. In addition, industry mobility is associated with higher hazard, suggesting that most overqualified workers who transition to a job match also changed employer and industry of work. Compared with established immigrants, nonimmigrants are more likely to move out of overqualification. Recent immigrants also have a much higher hazard than established immigrants for only the first 12 months, and then the effect quickly diminishes as the positive coefficient on recent immigrants (1.22) is offset by the negative coefficient on recent immigrants $* I(t>12$ month) $(-1.55)$.

There is no indication that the probabilities of transition over time are different between male and female workers or between university and college graduates. However, we find evidence that younger workers are more likely to transition out of a skills mismatch, compared with older working groups.

We also calculate marginal effects for the statistically significant variables. Table 4 shows that workers with short tenure transition out of overqualification in the first year 12 
TABLE 3: Determinants of transition from overqualification (Cox model).

\begin{tabular}{lccc}
\hline Variable & Coefficient & Standard error & Hazard ratio \\
\hline Training & 0.361 & $(0.093)^{* * *}$ & $(0.088)$ \\
Male & -0.018 & $(0.153)$ & 1.428 \\
University & -0.148 & $(0.196)^{* * *}$ & 0.982 \\
Short tenure & 2.581 & $(0.103)$ & 13.186 \\
Long tenure & -0.1555 & $(0.228)^{* * *}$ & 0.856 \\
Short tenure $* I$ (time $>12$ months) & -3.015 & $(0.511)^{* *}$ & 0.050 \\
Recent immigrant & 1.223 & $(0.189)^{*}$ & 3.246 \\
Nonimmigrant & 0.317 & $(0.628)^{*}$ & 1.373 \\
Recent immigrant $* I$ (time $>12$ months) & -1.559 & $(0.093)^{* * *}$ & 0.210 \\
Change industry & 0.948 & $(0.115)^{* *}$ & 2.582 \\
Age 25-34 & 0.264 & $(0.110)$ & 1.303 \\
Age 35-44 & 0.121 & DF & 1.128 \\
\hline Test of proportional hazard assumption & Chi-square & 12 \\
Global test & 13.65 & 0.3235 \\
\hline
\end{tabular}

Estimates significant at a $99 \%\left({ }^{* * *}\right), 95 \%\left({ }^{* *}\right)$, and $90 \%\left({ }^{*}\right)$ degree of confidence, not significant otherwise.

TABLE 4: Marginal effect of statistically significant variables ${ }^{4}$.

\begin{tabular}{lc}
\hline Variable & Marginal effect \\
\hline Training (from no to yes) & $43 \%$ \\
Short tenure and time $<12$ months & $1219 \%$ \\
Recent immigrant and time $<12$ & $224 \%$ \\
Nonimmigrant & $37 \%$ \\
Changing industry & $158 \%$ \\
Age 25-34 & $30 \%$ \\
Age 35-44 & $13 \%$ \\
\hline${ }^{4}$ Marginal effects represent the change in monthly transition hazard if the \\
variable is altered from the baseline and all other variables are held constant. \\
Baseline of the variables: no training, established immigrant, medium tenure, \\
same industry, and age group 45-54.
\end{tabular}

times faster than workers with medium or long tenure. Similarly, the transition hazard associated with recent immigrants is 224 percent higher than for established immigrants, but only within the first 12 months, while nonimmigrants record a 37 percent higher hazard than established immigrants for the whole five-year period. The marginal effects of job-related training and industry mobility on the transition probability are also significantly large. Taking job-related training increases the transition hazard by 43 percent, while industry movers are 158 percent more likely to have a transition. The chance of an individual aged from 25 to 34 to transition to a job match is also 30 percent higher than that of individuals aged 45 and over, while the probability of transition for workers aged from 35 to 44 increases by only about 13 percent.

Overall, global test results indicate that the proportional hazard assumption of the Cox model is met. In addition, using the fitted Cox regression model, Figure 3 examines the model fit by comparing observed and estimated survival probability (the probability an individual remaining overqualified over time) for the selected variables. In general, the model performs quite well. The results for other variables are available upon request.

\section{Summary and Conclusion}

The extent to which overqualification persists over time determines the real economic costs of skills mismatch. However, there is very little work done in Canada on the persistence of skill mismatch. There is also very little known about how the depreciation of human capital induced by overqualification affects the probability of transitioning to a correct job match.

In this paper, we have investigated the duration of skills mismatch and found that a significant proportion of workers who are overqualified for their job persistently remain in such a state for a long time. Eventually the situation becomes permanent. We found that an overqualified worker has a 22 percent probability of transitioning to an occupation that matches the education level within a 5-year period. While the majority of individual spells of overqualification is permanent, the fact that the probability of transition quickly decreases over time confirms that overeducated individuals lose some of their skills and knowledge that are not used in their job and hence the probability of finding a job match decreases over time. Our findings support the assumption that unused skills and knowledge quickly depreciate over time and significantly reduce the transition probability of overeducated individuals.

While recent immigrants transition faster than established immigrants in the first 12 months, nonimmigrants have a higher probability of transition than established immigrants for the whole period. Changing industry of work doubles the chance of transition and workers have a better chance to transition out of overqualification when they are young.

Regression analyses provide evidence that recent overqualified workers (on average 7 months tenure) are more likely to transition than medium to long tenure workers, but 


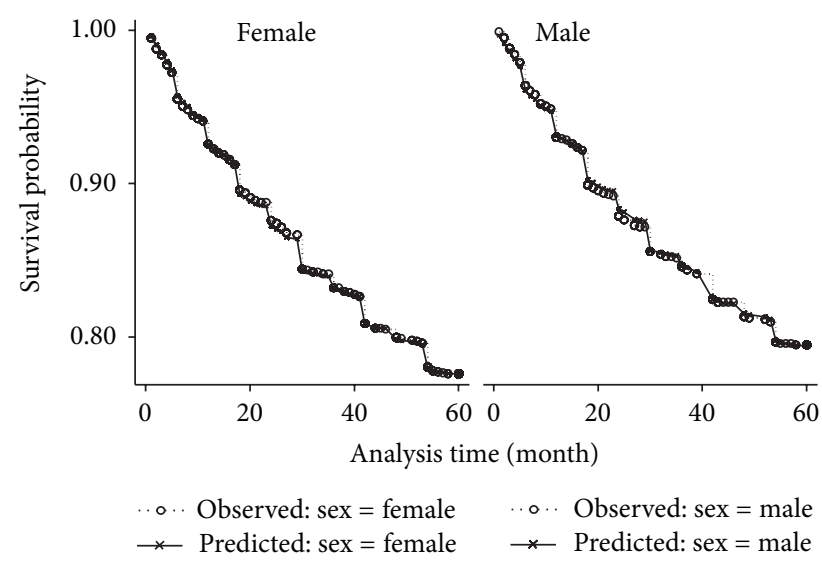

(a)

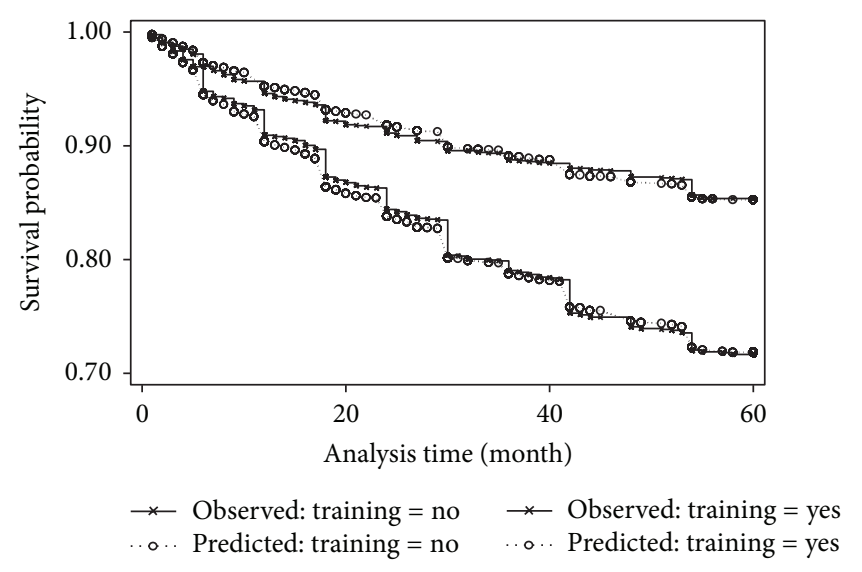

(b)

FIgURE 3: Model performance check.

only within the first year. These results also confirm the existence of the cut-off time point $\tau$, after which the remaining overqualified workers become no longer attractive to employers from the skilled jobs.

Workers accepting job-related training are found to have a 43 percent higher monthly transition hazard, suggesting that job-related training is an effective way to restock human capital and improve the chance to work in a skilled job.

Typically, wage increases associated with transitions are substantial, suggesting that overeducated workers in lowskilled jobs prefer to work in high-skilled jobs because they can receive higher wages. However, once an overeducated individual works in a low-skilled job, the probability of transition quickly decreases over time. After a 19-month period, an overeducated individual no longer satisfies the skill requirement for level $\mathrm{A}$ or $\mathrm{B}$ occupations and overqualification spells becomes permanent. Finally, taking job-related training significantly raises the probability of transition.

\section{Disclaimer}

Views expressed herein are those of the authors and do not necessarily reflect those of HRSDC.

\section{Conflict of Interests}

The authors declare that there is no conflict of interests regarding the publication of this paper.

\section{Acknowledgment}

The authors wish to thank Gilles Bérubé, Mohsen Bouaissa, Jeff Carr, and two anonymous referees for useful comments. The authors are solely responsible for any errors remaining.

\section{References}

[1] J. Carr and X. Chen, What is the Incidence of OccupationEducation mIsmatch in Canada and What are Its Consequences?
Policy research directorate, Human Resources and Skills Development Canada, 2011.

[2] Organisation for Economic Co-operation and Development (OECD 2011), Right for the Job: Over-Qualified or Under-Skilled? OECD Publishing, Paris, France.

[3] F. Green, S. McIntosh, and A. Vignoles, "Overeducation and Skills-Clarifying the concepts," Centre for Economic Performance, Discussion Paper 435, 1999.

[4] W. R. Johnson, "A theory of job shopping," Quarterly Journal of Economics, vol. 92, no. 2, pp. 261-278, 1978.

[5] B. Jovanovic, "Job matching and the theory of turnover," Journal of Political Economy, vol. 87, no. 5, pp. 972-990, 1979.

[6] M. Spence, "Job market signaling," The Quarterly Journal of Economics, vol. 87, no. 3, pp. 355-374, 1973.

[7] C. A. Pissarides, Equilibrium Unemployment Theory, Basil Blackwell Ltd, Cambridge, Mass, USA, 1990.

[8] B. Petrongolo and C. A. Pissarides, "Looking into the black box: a survey of the matching function," Journal of Economic Literature, vol. 39, no. 2, pp. 390-431, 2001.

[9] J. Muysken and B. T. Weel, Overeducation and Crowding Out of Low-Skilled Workers, Department of Economics and MERIT, Maastricht University, Maastricht, The Netherlands, 2000.

[10] C. A. Pissarides, "Loss of skill during unemployment and the persistence of employment shocks," The Quarterly Journal of Economics, vol. 107, no. 4, pp. 1371-1391, 1992.

[11] T. J. Devine and N. M. Kiefer, Empirical Labor Economics: the Search Approach, Oxford University Press, New York, NY, USA, 1991.

[12] J. J. Heckman and G. J. Borjas, "Does unemployment cause future unemployment? Definitions, questions and answers from a continuous time model of heterogeneity and state dependence," Economica, London School of Economics and Political Science, vol. 47, no. 187, pp. 247-283, 1980.

[13] M. Frenette, "Overqualified? Recent graduates and the needs of their employers," Education Quarterly Review, vol. 7, no. 1, Statistics Canada Catalogue no. 81-003-XIE, 2000.

[14] M. Frenette, "The overqualified Canadian graduate: the role of the academic program in the incidence, persistence, and economic returns to overqualification," Economics of Education Review, vol. 23, no. 1, pp. 29-45, 2004. 
[15] R. Finnie, “'Graduates' earnings and the job skills-education match," Education Quarterly Review, vol. 7, Statistics Canada, no. 2, 2001.

[16] P. Dolton and A. Vignoles, “The incidence and effects of overeducation in the U.K. Graduate labour market," Economics of Education Review, vol. 19, no. 2, pp. 179-198, 2000.

[17] S. Rubb, "Overeducation: a short or long run phenomenon for individuals?" Economics of Education Review, vol. 22, no. 4, pp. 389-394, 2003.

[18] A. Böhlmark, Over-and Undereducation in the Swedish Labour Market. Incidence, Wage Effects and Characteristics 1968-2000, Swedish Institute for Social Research (SOFI), Stockholm University, 2003.

[19] S. McGuinness and M. Wooden, "Overskilling, job insecurity and career mobility," IZA Discussion Paper 2938, 2007.

[20] T. Schatteman and D. Verhaest, "Proceedings of the Overeducation in the early career: an analysis using sequence techniques," in 15th European Research Network on Transitions in Youth conference, Ghent, Belgium, 2007.

[21] A. de Grip and J. van Loo, "The economics of skills obsolescence: a review," Research in Labor Economics, vol. 21, pp. 1-26, 2002.

[22] J. Hartog, "Over-education and earnings: where are we, where should we go?" Economics of Education Review, vol. 19, no. 2, pp. 131-147, 2000.

[23] D. R. Cox, "Regression models and life-tables," Journal of the Royal Statistical Society B, vol. 34, no. 2, pp. 187-220, 1972.

[24] R. H. Frank, "Why women earn less: the theory and estimation of differential overqualification," American Economic Review, vol. 68 , no. 3, pp. 360-373, 1978. 